\title{
Using Near-infrared reflectance spectroscopy (NIRS) to predict glucobrassicin concentrations in cabbage and brussels sprout leaf tissue
}

Ilse E. Renner ${ }^{1}$ and Vincent A Fritz $2^{2^{*}}$

\begin{abstract}
Background: Glucobrassicin (GBS) and its hydrolysis product indole-3-carbinol are important nutritional constituents implicated in cancer chemoprevention. Dietary consumption of vegetables sources of GBS, such as cabbage and Brussels sprouts, is linked to tumor suppression, carcinogen excretion, and cancer-risk reduction. High-performance liquid-chromatography (HPLC) is the current standard GBS identification method, and quantification is based on UV-light absorption in comparison to known standards or via mass spectrometry. These analytical techniques require expensive equipment, trained laboratory personnel, hazardous chemicals, and they are labor intensive. A rapid, nondestructive, inexpensive quantification method is needed to accelerate the adoption of GBS-enhancing production systems. Such an analytical method would allow producers to quantify the quality of their products and give plant breeders a high-throughput phenotyping tool to increase the scale of their breeding programs for high GBS-accumulating varieties. Near-infrared reflectance spectroscopy (NIRS) paired with partial least squares regression (PLSR) could be a useful tool to develop such a method.
\end{abstract}

Results: Here we demonstrate that GBS concentrations of freeze-dried tissue from a wide variety of cabbage and Brussels sprouts can be predicted using partial least squares regression from NIRS data generated from wavelengths between 950 and $1650 \mathrm{~nm}$. Cross-validation models had R $=0.75$ with RPD $=2.3$ for predicting $\mu \mathrm{mol} \mathrm{GBS} \cdot 100 \mathrm{~g}^{-1}$ fresh weight and $\mathrm{R}^{2}=0.80$ with $\mathrm{RPD}=2.4$ for predicting $\mu \mathrm{mol} \mathrm{GBS} \cdot \mathrm{g}^{-1}$ dry weight. Inspections of equation loadings suggest the molecular associations used in modeling may be due to first overtones from $\mathrm{O}-\mathrm{H}$ stretching and/or $\mathrm{N}-\mathrm{H}$ stretching of amines.

Conclusions: A calibration model suitable for screening GBS concentration of freeze-dried leaf tissue using NIRSgenerated data paired with PLSR can be created for cabbage and Brussels sprouts. Optimal NIRS wavelength ranges for calibration remain an open question.

Keywords: Glucobrassicin, Brassica oleracea, Cabbage, Brussels sprouts, Near-infrared spectroscopy, Chemometrics, Partial least squares regression, Chemoprevention

*Correspondence: vafritz@umn.edu

2 Southern Research and Outreach Center, University of Minnesota, Waseca, MN 56093, USA

Full list of author information is available at the end of the article

\section{Background}

The genus Brassica, which includes commonly consumed vegetables such as cabbage and Brussels sprouts, produce a class of cancer-preventing compounds known as glucosinolates (GSLs). GSL quantification is necessary to determine the health-promoting benefit of

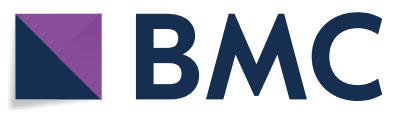

(c) The Author(s) 2020. This article is licensed under a Creative Commons Attribution 4.0 International License, which permits use, sharing, adaptation, distribution and reproduction in any medium or format, as long as you give appropriate credit to the original author(s) and the source, provide a link to the Creative Commons licence, and indicate if changes were made. The images or other third party material in this article are included in the article's Creative Commons licence, unless indicated otherwise in a credit line to the material. If material is not included in the article's Creative Commons licence and your intended use is not permitted by statutory regulation or exceeds the permitted use, you will need to obtain permission directly from the copyright holder. To view a copy of this licence, visit http://creativeco mmons.org/licenses/by/4.0/. The Creative Commons Public Domain Dedication waiver (http://creativecommons.org/publicdomain/ zero/1.0/) applies to the data made available in this article, unless otherwise stated in a credit line to the data. 
fresh vegetables. Current quantification methods are time-consuming, destructive, hazardous, and expensive. Consequently, this limits the timely application of GSL-enhancing technologies. Alternative methods that address these limitations will help usher in new markets for GSL-enhanced vegetables and increase the screening capacity of high-GSL vegetable breeding programs.

GSLs are nitrogen- and sulfur-containing secondary compounds produced by plants of the order Brassicales, and they are particularly abundant in the economically important Brassicaceae family [1]. GSL hydrolysis products are toxic to many pests and thereby protect the plant against herbivores and pathogens [2, 3]. Across all known GSL-containing plants, 88 individual GSLs have been directly identified using nuclear magnetic resonance spectroscopy and mass spectrometry, and the identities of an additional 49 GSLs have been inferred using indirect chemical elucidation methods based on GSL breakdown products [4]. Of these, a handful of individual GSL hydrolysis products have been implicated in cancer prevention [5].

Hydrolysis of GSLs occurs via the endogenous plant enzyme myrosinase (thioglucoside glucohydrolase, EC 3.2.1.147) and results in a suite of bioactive compounds such as isothiocyanates, indoles, nitriles, thiocyanates, epithionitriles, and oxazolidines [6]. The fate of the hydrolyzed compound depends on the parent GSL molecule and the environment during hydrolysis. The indole-3-carbinol compound derived from the parent GSL, glucobrassicin (GBS), has been the subject of chemoprevention research [7]. Dr. Lee Wattenberg, at the University of Minnesota, laid the groundwork for chemoprevention research using vegetable constituents from Brassica species. Wattenberg found that mice fed diets rich in Brussels sprouts and cabbage had greater carcinogen detoxification capabilities than mice that ate a noncruciferous diet [8]. This capability was later attributed to indole-3-carbinol [9]. Indol-3-carbinol has suppressed tumors in mice [10]. It also increased the rate of carcinogen metabolism and excretion in mouse models [11], and this effect was subsequently demonstrated in humans [12]. It is widely thought that increasing GBS consumption could be an effective way to prevent cancer development and progression [13].

GSL profiles and concentrations are affected by genotype, the environment, and genotype by environment interactions [14]. In Brussels sprouts and cabbage, GBS dominates the GSL profile $[15,16]$, which makes these specific vegetables excellent targets for GBS-enhancing production systems and breeding efforts. Currently, high-performance liquid-chromatography (HPLC) is the standard GSL quantification method [17]. HPLC allows for chemical separation, and chemical quantification is calculated based on the absorbance of a chemical peak multiplied by a response factor of a known concentration of an internal or external standard, or via mass spectrometry. It is expensive, time consuming, requires hazardous chemicals, and is plant destructive. An alternative method, such as near-infrared reflectance spectroscopy (NIRS) analysis, is relatively inexpensive, rapid, does not require hazardous chemicals, and is nondestructive. It does not allow for chemical quantification, and so calibration through chemometric techniques is needed to estimate chemical concentrations.

NIRS is a form of vibrational spectroscopy utilizing wavelengths between 780 and $2500 \mathrm{~nm}$. This radiation causes molecular vibrations especially in $\mathrm{C}-\mathrm{H}, \mathrm{O}-\mathrm{H}$, and $\mathrm{N}-\mathrm{H}$ bonds. The transmission or reflectance is detected and recorded, and it corresponds to overtone and combination bands of fundamental molecular vibrations [18]. The vibrations are characteristic of specific molecules, however; the bands are usually broad, so it can be difficult to assign specific chemical information to a spectrum. In order to overcome this, special statistical approaches known as chemometrics can be applied to NIR spectra to extract useful information for estimating the reference values. NIRS has developed into a useful agronomic tool largely due to the work of Karl Norris of the USDA. In the 1960 's, Norris designed a pioneering spectrometer to measure moisture, oil, and protein content of agronomic crops [19]. The development of such analytical techniques opened the door for the field of chemometrics which led to the creation of a wide range of NIRS calibration models for high-throughput phenotyping.

Partial least squares regression (PLSR) has been widely applied to NIRS data and is one of the most common chemometric techniques [20]. PLSR has been used successfully to develop calibration models for GSLs in seeds of Brassicaceae using NIRS data [21]. Unlike multiple linear regression which would over-fit a model when the number of factors far outnumbers the number of observations, PLSR can be used in these cases which often arise from spectral data. It also improves upon multiple linear regression due to its ability to handle collinearity between predictor variables and does not assume that the predictors are fixed. PLSR attempts to extract latent factors to account for the maximum variation in the independent variables. From the latent structure, a set of components describing the maximum correlation between predictors and response variables is selected [22] from which to create a linear model. Other methods have also been used for calibration model development of GSLs including modified PLSR which attempts to remove explanatory variables that are irrelevant to the response. The modified PLSR is cited as having lower errors than PLSR [23] but is a less commonly used approach. 
NIRS has been applied to measuring GSL concentrations from seed tissue with excellent success, and this is now a common method for seed GSL quantification [24]. Since humans eat leaf tissue of cabbage and Brussels sprouts rather than the seeds, having quantification methods for leaf tissue is more relevant. NIRS quantification of GSLs from leaf tissue however has not been well studied. We are aware of only six publications that reported using NIRS to develop quantitative calibration models for various GSLs in leaf tissue [25, 30]. Only four of these studies reported calibration models for GBS specifically (Table 1). Of those, Sahamishirazi et al. [27] reported a model that had poor performance in broccoli florets. In B. rapa leaf tissue, Font et al. [28] were able to determine low or high GBS concentrations for screening purposes. Hernandez-Hierro et al. [29] developed a calibration model for GBS in broccoli that they suggested would be useful for screening, but they did not elaborate further. The most useful calibration model for determining GBS quantitatively was developed by Chen et al. [30] in B. albograbra (Chinese kale) leaf tissue at various stages of maturity. The model performance of these published studies is summarized in Table 2. No useful

Table 1 Reference GBS concentrations ( $\mu \mathrm{mol} \mathrm{g}^{-1}$ dry weight) in vegetative tissue in previously reported GBS calibrations

\begin{tabular}{llrlll}
\hline Citation & Tissue & n & Minimum & Maximum & $\begin{array}{l}\text { Standard } \\
\text { deviation }\end{array}$ \\
\hline$[27]$ & Broccolifloret & 100 & 0.21 & 0.73 & 0.24 \\
{$[28]$} & Rapeseed leaf & 115 & 0.06 & 3.45 & 0.83 \\
{$[29]$} & Broccolifloret & 46 & 0.68 & 7.18 & 1.09 \\
{$[30]$} & Chinese kale leaf & 145 & $0^{*}$ & $26^{*}$ & 4.68
\end{tabular}

*Actual values not reported. Values here are estimated from figures presented in the cited publication equations have been developed using cabbage or Brussels sprouts leaf tissue, which would be of interest as these varieties tend to produce the highest GBS concentrations, making them targets for breeders focusing on developing high GBS yielding cultivars or for quality assessment purposes in value-added markets. The purpose of this study was to develop a GBS calibration equation from a wide variety of cabbages and Brussels sprouts using the open source software R Statistic.

\section{Results and discussion}

\section{Reference glucobrassicin (GBS) values}

Models based on both fresh weight and dry weight GBS concentrations were developed. Reference values were attained using desulphated GBS which was identified based on retention time (Fig. 1) and compared to a desulphated GBS potassium salt standard (Product \#80593, PhytoLab, Vestenbergsgreuth, Bavaria, Germany). The predominant GSL peak across the samples used for this study was that of GBS. GBS values on a dry weight basis were back calculated based on the fresh weight to dry weight ratio of the sample. The average GBS concentration on a fresh weight basis from a sample size of 92 was $65.16 \mu \mathrm{mol} \cdot 100 \mathrm{~g}^{-1}$ with a range of $3.69-379.16 \mu \mathrm{mol} \cdot 100 \mathrm{~g}^{-1}$. The average GBS concentration on a dry weight basis was $5.33 \mu \mathrm{mol} \cdot 100 \mathrm{~g}^{-1}$ with a range of 0.41 to $22.25 \mu \mathrm{mol} \cdot 100 \mathrm{~g}^{-1}$. Standard deviations of the reference values were $80.01 \mu \mathrm{mol} \cdot 100 \mathrm{~g}^{-1}$ and $4.95 \mu \mathrm{mol} \cdot \mathrm{g}^{-1}$ on a fresh weight and dry weight basis respectively. Fresh weight GBS concentrations of the reference values were most abundant at lower concentrations (Fig. 2). GBS concentrations on a dry weight basis had a somewhat improved frequency distribution. This may explain the better performance of the GBS prediction model based on dry weight GBS concentrations. In comparison to the four other studies that developed

Table 2 Model statistics from previously reported GBS calibration models using vegetative tissue with modified PLS regression

\begin{tabular}{|c|c|c|c|c|c|c|}
\hline \multirow[t]{2}{*}{ Citation } & \multirow[t]{2}{*}{ Tissue } & \multicolumn{2}{|c|}{ Calibration } & \multicolumn{3}{|c|}{ Cross-validation } \\
\hline & & $\mathrm{R}_{\text {cal }}^{2}$ & $\mathrm{SEC}^{\mathbf{b}}$ & $\mathrm{R}_{\mathrm{CV}}^{\mathrm{c}}$ & SD.SECV ${ }^{-1 d}$ & Terms $^{\mathbf{e}}$ \\
\hline$[27]$ & Broccoli floret & $N R$ & 0.21 & 0.11 & 0.80 & 6 \\
\hline$[28]$ & Rapeseed leaf & 0.50 & 0.59 & 0.41 & 1.29 & 3 \\
\hline$[29]$ & Broccoli floret & 0.89 & 0.35 & $N R$ & 2.10 & 7 \\
\hline$[30]$ & Chinese kale leaf & $N R$ & $N R$ & 0.93 & 3.84 & $N R$ \\
\hline
\end{tabular}

a Coefficient of determination of the calibration

b Standard error of calibration

c Coefficient of determination of the cross validation

d Ratio of the standard deviation of the reference data to the standard error of the cross validation

e Number of terms used in the model selected for cross-validation

$N R$ not reported 


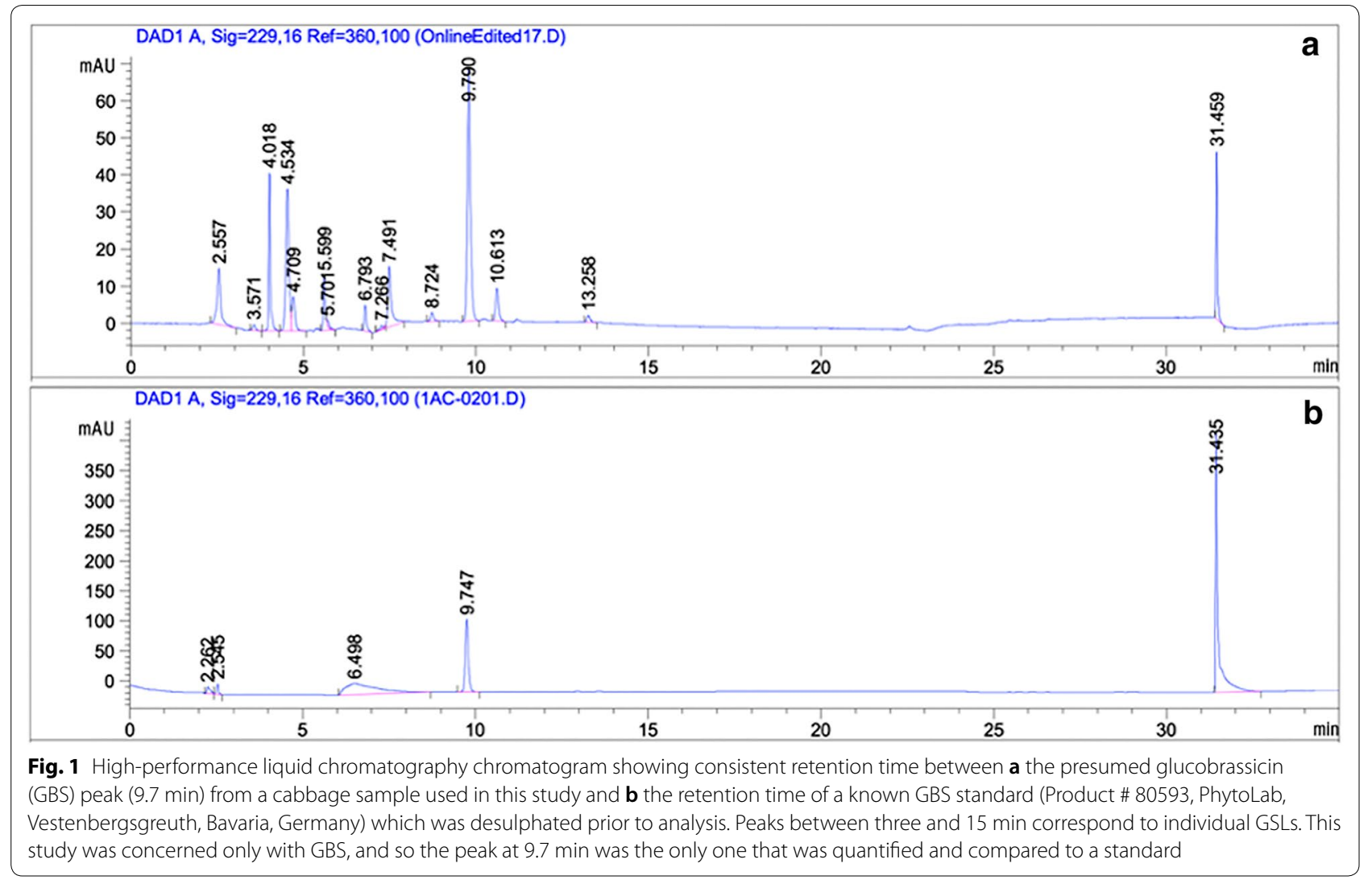

calibration models for GBS in the typically consumed components of Brassica vegetables, we used a wider range of GBS concentrations (Table 3) than the other studies (Table 1) with the exception of Chen et al. [30] who had a similar range but a slightly more right-skewed distribution.

\section{Model development}

Models were developed using the raw spectral data (log $1 /$ reflectance) as well as on spectra subjected to several preprocessing techniques (Fig. 3). This included (1) taking the standard normal variate (SNV) and de-trending the raw spectral data, (2) taking the first derivative of the raw spectral data, and (3) applying the SNV plus detrending to the first derivative. The SNV helps compensate for spectral slope and partial size variation while de-trending can remove trends in the spectra [31]. Derivatization can remove the effects of offsets between spectra but does not adjust for baseline slope or scattering effect. Applying the SNV with de-trending to the spectral data has reportedly achieved calibration correlation statistics which were superior to raw or derivative spectra [32]. However, SNV plus de-trending in the present study did not improve calibration statistics, but rather it drastically impaired the model (Table 4). Models we developed on the first derivative of the raw spectral data were very similar to those built with no preprocessing.

Calibrations equations were developed using a training data set $(n=68)$ and the equations were internally cross-validated with a testing data set $\left(n_{\text {test }}=24\right)$. The data sets were divided using a stratified random sampling procedure so that the testing data set was representative of the training data set. Calibration models were developed by PLSR with a leave-one-out cross-validation method. The leave-one-out method iteratively subsets the training data set into two data sets of with $\mathrm{n}_{\text {train }}-1$ and 1 observations. To accomplish this, a single data point is removed and acts as a validation data point, and this process occurs iteratively until all observations in the training data set have been used for validation. This processes therefore occurs $n_{\text {train }}$ times. The PLS components used in each model were selected using the one-sigma heuristic [33]. This allows the selection of the fewest number of PLS components which are less than one standard error away from the model that fits the data best overall. Component selection is important because incorporating more components results in lower error (RMSEC) but including too many components can result in model overfitting [34]. Spectral data were scaled and centered automatically using the PLS function in R Statistic. 

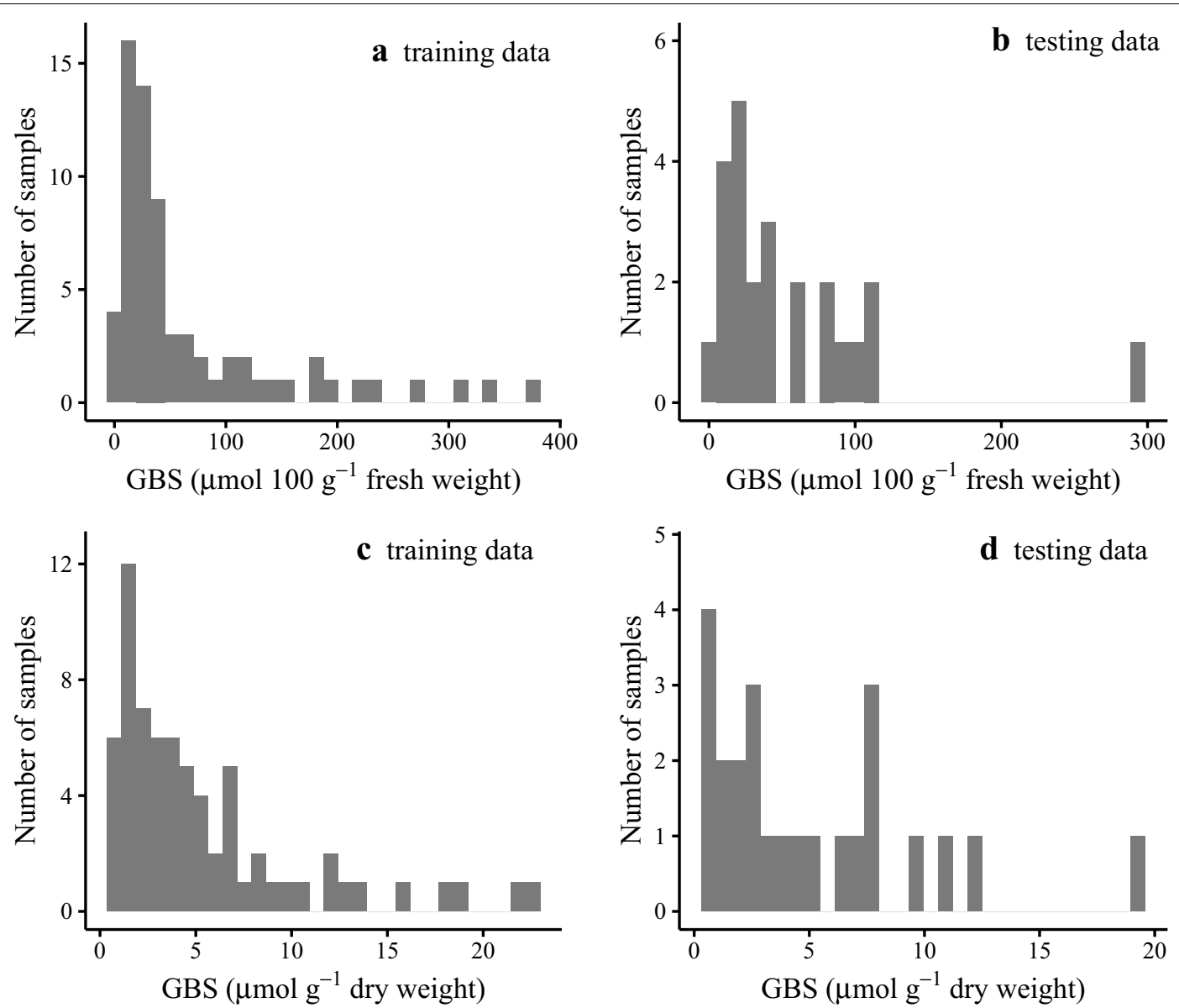

Fig. 2 Frequency distributions of the glucobrassicin (GBS) concentrations on a fresh weight basis $\left(\mu \mathrm{mol} \cdot 100 \mathrm{~g}^{-1)}\right.$ and a dry weight basis $\left(\mu \mathrm{mol} \cdot \mathrm{g}^{-1}\right.$ ) for the training $(n=68)$ and testing $(n=24)$ data subsets used for calibration and cross validation respectively. Samples were derived from cabbage and Brussels sprouts leaf tissue purchased from grocery stores and natural food cooperatives in Minneapolis and Saint Paul, MN. Vegetables were purchased between August and October, 2019. Concentrations were determined using high-performance liquid chromatography and UV-spectroscopy. Plots show the number of samples within a range of GBS concentrations on a fresh weight basis from the $\mathbf{a}$ training data set and $\mathbf{b}$ the testing data set and frequency distributions of GBS concentrations on a dry weight basis from the $\mathbf{c}$ training data set and $\mathbf{d}$ the testing data set

Table 3 Reference values of GBS concentration from samples used in this study $(n=92)$

\begin{tabular}{lllll}
\hline $\begin{array}{l}\text { Basis of GBS } \\
\text { concentration }\end{array}$ & Minimum & Maximum & Mean & $\begin{array}{l}\text { Standard } \\
\text { deviation }\end{array}$ \\
\hline $\begin{array}{l}\text { Fresh weight }(\mu \mathrm{mol} \\
\left.\text { GBS } 100 \mathrm{~g}^{-1}\right)\end{array}$ & 3.69 & 379.16 & 65.16 & 80.01 \\
$\begin{array}{l}\text { Dry weight }\left(\mu \mathrm{mol} \mathrm{GBS} \cdot \mathrm{g}^{-1}\right) \\
\text { ( }\end{array}$ & 0.41 & 22.25 & 5.33 & 4.95 \\
\hline
\end{tabular}

Models can be assessed on the cross-validation coefficient of determination $\left(\mathrm{R}_{\mathrm{CV}}^{2}\right)$ and on the ratio of prediction to deviation (RPD) which is calculated by dividing the standard deviation from the values of the reference method by the root mean squared error of prediction of the cross-validation (RMSEC). Models with RPD values between 2.0 to 2.5 are considered acceptable for qualitative screening into "high", "medium", or "low" groups. RPD values greater than 3.0 are considered excellent for quantification, whereas those with values less than 2.0 are generally not useful [35].

\section{Predicting GBS concentrations}

The raw spectral data and the first derivative models outperformed models which applied SNV plus de-trending preprocessing (Table 4). The coefficient of determination of the cross validation $\left(\mathrm{R}_{\mathrm{CV}}^{2}\right)$ and the residual predictive deviation (RPD) were 0.75 and 2.3 compared to 0.76 and 2.6 for the raw and first derivative spectra respectively when predicting $\mu \mathrm{mol}$ GBS $100 \mathrm{~g}^{-1}$ fresh weight. The dry weight basis models were similar to the fresh weight basis 


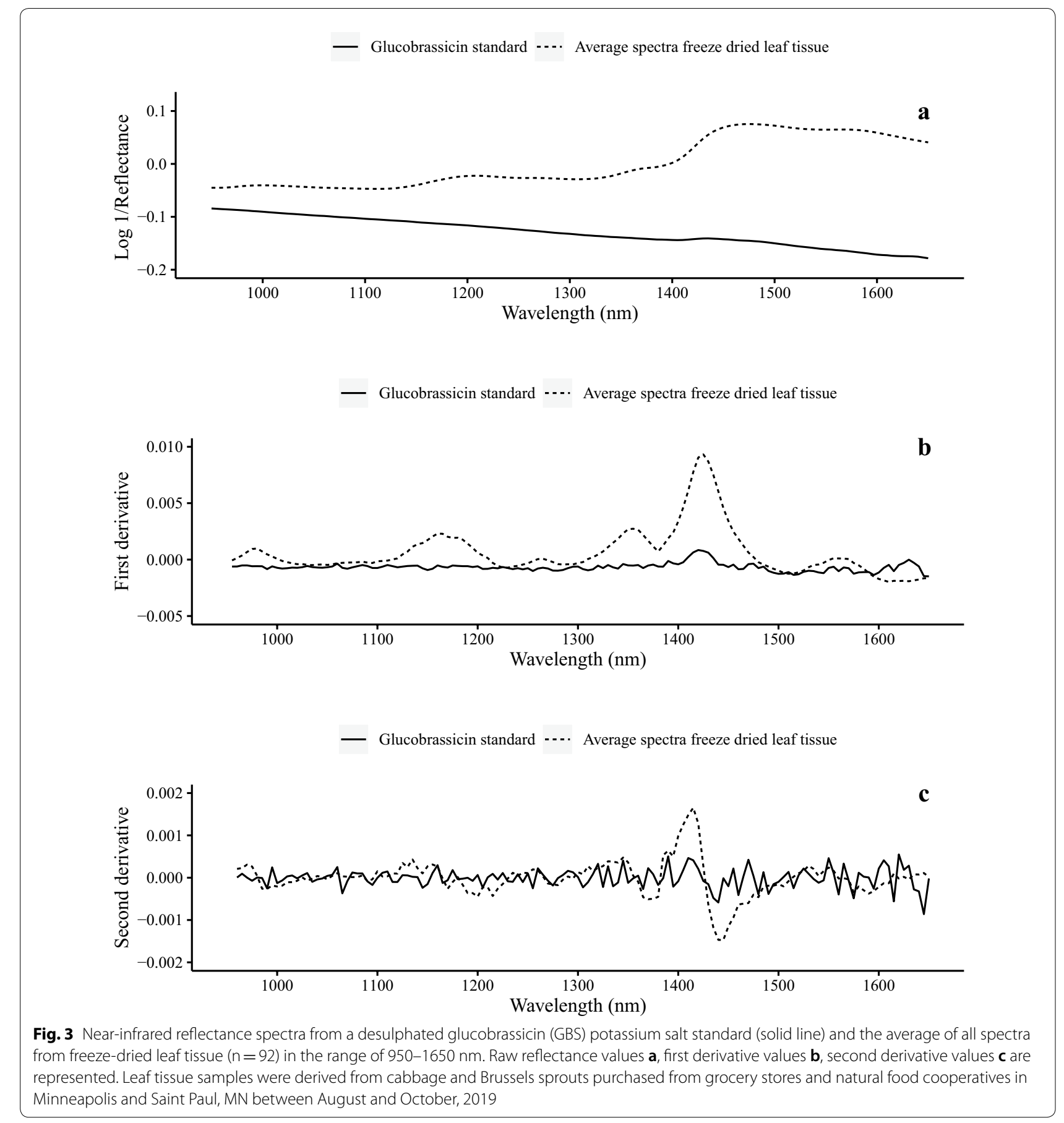

models. The $\mathrm{R}_{\mathrm{CV}}^{2}$ and RPD were 0.80 and 2.4 compared to 0.79 and 2.4 for the raw and first derivative spectra, respectively. The number of components included in the model was 10 for those built using the raw spectral data but six for the models built using the first derivative spectra. Since both the raw and derivatized spectra resulted in similar models, the predicted versus measured GBS concentrations using the values derived from the model using the raw spectra are shown in Fig. 4. The RPD values are similar to the SD/SECV metric reported from similar studies and included in Table 2. Both the fresh weight and dry weight basis models could be used to screen samples of cabbage and Brussels sprout leaf tissue for GBS concentration. The model developed here is different from other similar studies in a few important ways. The range of wavelengths used here is smaller than similar studies 
Table 4 Model statistics for predicting GBS concentration on a fresh weight and dry weight bases

\begin{tabular}{|c|c|c|c|c|c|c|}
\hline \multirow[t]{2}{*}{ Spectral data used for model development } & \multicolumn{2}{|c|}{ Calibration $(n=68)$} & \multicolumn{4}{|c|}{ Cross-validation $(n=24)$} \\
\hline & $\mathrm{R}_{\text {cal }}^{2}$ & RMSEC $^{\mathbf{b}}$ & $\mathrm{R}_{\mathrm{CV}}^{2}$ & RMSEPd $^{d}$ & $\mathrm{RPD}^{\mathrm{e}}$ & Terms $^{f}$ \\
\hline Raw (fr wt) & 0.89 & 40.47 & 0.75 & 35.12 & 2.3 & 10 \\
\hline Raw (dr wt) & 0.90 & 2.17 & 0.80 & 2.07 & 2.4 & 10 \\
\hline Raw plus SNV + DT (fr wt) & 0.65 & 53.61 & 0.60 & 39.56 & 2.0 & 2 \\
\hline Raw plus SNV + DT (dr wt) & 0.63 & 3.67 & 0.41 & 3.46 & 1.4 & 2 \\
\hline $1^{\text {st }}$ derivative (fr wt) & 0.89 & 43.29 & 0.76 & 30.44 & 2.6 & 6 \\
\hline $1^{\text {st }}$ derivative (dr wt) & 0.90 & 2.41 & 0.79 & 2.07 & 2.4 & 6 \\
\hline $1^{\text {st }}$ derivative plus SNV $+\mathrm{DT}^{g}(\mathrm{fr} \mathrm{wt})$ & 0.76 & 53.10 & 0.55 & 42.17 & 1.9 & 2 \\
\hline $1^{\text {st }}$ derivative plus SNV + DT (dr wt) & 0.64 & 3.22 & 0.46 & 3.33 & 1.5 & 1 \\
\hline
\end{tabular}

a Coefficient of determination of the calibration

b Root mean squared error of calibration

c Coefficient of determination of the cross-validation

d Root mean squared error of prediction

e Ratio of prediction to deviation

${ }^{f}$ Number of terms (PLS components) used in the model selected for cross-validation

g Standard normal variate with detrending spectral preprocessing
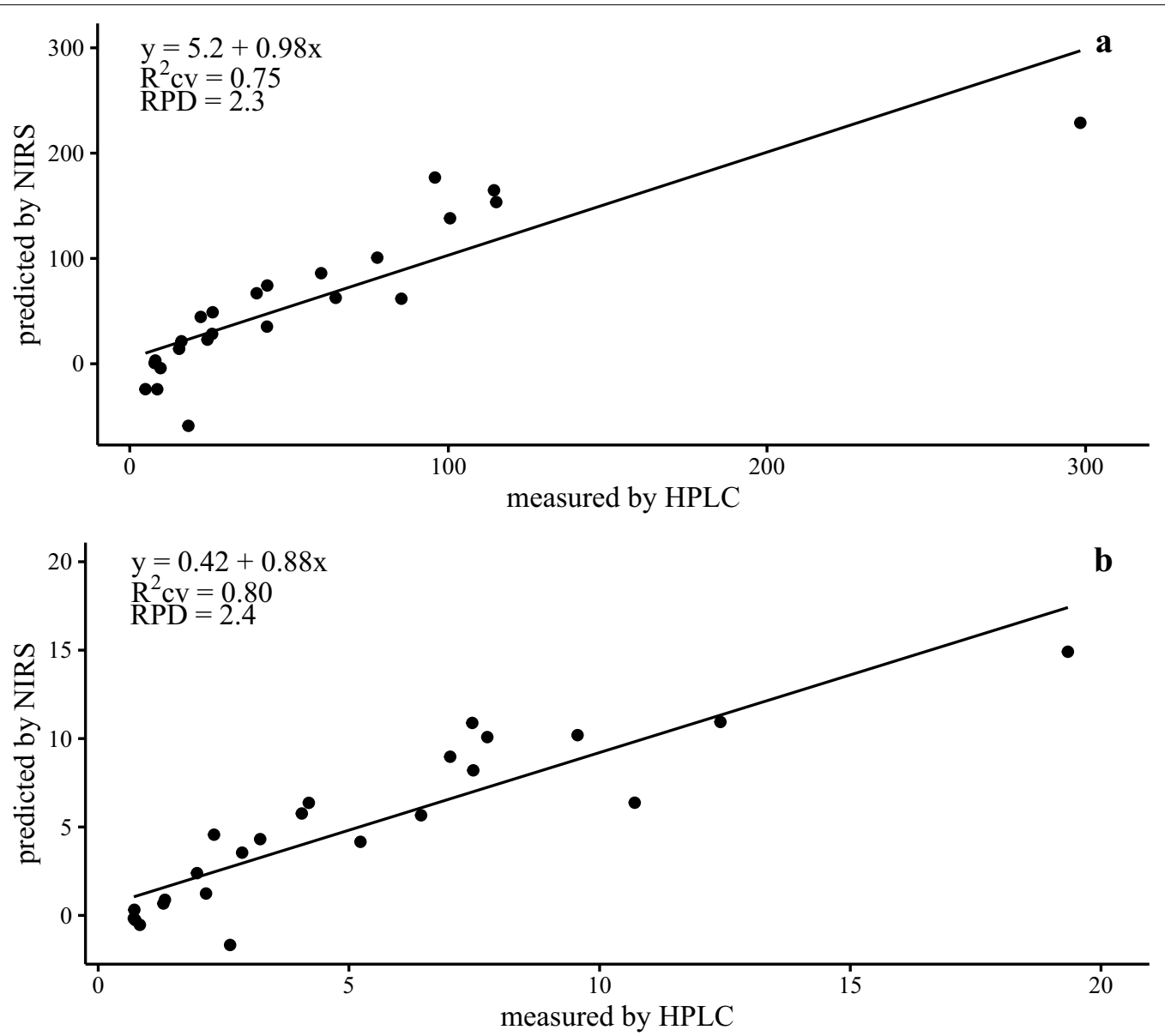

Fig. 4 Cross-validation scatter plots ( $n=24$ ) of glucobrassicin (GBS) concentration determined using high-performance liquid chromatography and UV-spectroscopy vs. near-infrared reflectance spectroscopy predicted GBS values for $\mathbf{a} \mu \mathrm{mol}$ GBS. $100 \mathrm{~g}^{-1}$ fresh weight, and $\mathbf{b} \mu \mathrm{mol}$ GBS. $\mathrm{g}^{-1} \mathrm{dry}$ weight. Models were developed from raw spectral data using partial least squares regression 
(950-1650 nm compared to $400-2500 \mathrm{~nm}$ ) and we used PLSR in R Statistic compared to all other similar studies which used modified PLSR in Win ISI software (Infrasoft International, LLC, Port Matilda, PA). Additionally, the reference chemistry method used here was based on fresh samples and not on freeze-dried powders.

\section{NIR spectra and loading plots}

Spectral features can be attributed to characteristic molecular vibrations, and these are seen in sample spectra. The features can be interpreted based on chemical knowledge of molecular bands. Calibration loading plots indicate which wavelengths contribute most to each component in the model, and so comparisons between the spectral features and the major wavelengths contributing to the loading plots help define what molecular characteristics are being used for predictions. The average spectra from the freeze-dried leaf tissue compared to the GBS potassium salt standard spectra have similar bands around wavelengths 1420 and $1425 \mathrm{~nm}$ (Fig. 3) which corresponds with the first overtone from $\mathrm{O}-\mathrm{H}$ stretching, but these bands were not clearly present in the loading plots (Fig. 5) of the first three components. The first overtone of the indole $\mathrm{N}-\mathrm{H}$ asymmetric stretching is associated with a band around 1450 [18]. This was present in all three model component loadings and evident in the average freeze-dried spectra second derivative plot (Fig. 3) and is a distinctive bond in the GBS molecule. However, this region also contains the moisture associated bands of the first overtone from $\mathrm{O}-\mathrm{H}$ stretching which occurs between 1440-1470 nm [18].

\section{Conclusions}

The models reported here outperform several others [27, 29]. The model developed by Chen et al. [30] performed better than the present study, and it was useful for qualitative determination of GBS in Chinese kale. The model by Chen et al. [30] was built using a wider wavelength range and a greater sample size which could contribute to its better accuracy, although this is not completely clear as there are currently very few studies aimed at the development of GBS calibration models on vegetative tissue. Additionally, the broad, diverse origin of a large number of cultivars that we obtained to develop this model may contribute to higher error compared to that seen by Chen et al. [30]. Arguably, our models would more accurately reflect the diversity of materials breeders, producers, and processors would encounter in utilizing NIRS to characterize GBS concentrations for their particular needs.

NIR spectrometers utilizing the wavelengths between 950 and $1650 \mathrm{~nm}$ successfully generated spectra useful in PLSR model development for GBS screening of freezedried leaf tissue, a range that is narrower than previously generated NIRS calibration models. Additionally, spectra generated from freeze-dried tissue can be used to successfully estimate GBS concentrations on a freshweight basis from a wide variety of cabbages and Brussels sprouts. Predicting GBS concentrations in Brassica leaf tissue is possible with the development of calibration models using PLSR applied to NIRS data. Refinement of such models will help accelerate the adoption of GBSenhancing production practices by allowing producers to verify product quality and thereby achieve premium prices. It will also help increase the scale and efficiency of breeding programs for high GBS-accumulating cultivars. Future work should address which wavelengths or regions of the NIR spectrum are best at predicting GBS concentrations. Doing so could support the development of small, hand-held NIRS devices.

\section{Materials and methods Plant samples}

This study was conducted using cabbage (Brassica oleracea var. capitata) and Brussels sprouts (Brassica oleracea var. gemmifera) purchased from supermarkets and natural food cooperatives located in Minneapolis and Saint Paul, Minnesota, between August and October, 2019. To capture a wide range of variation in GBS concentrations, samples were selected for variation in size, pigment, and when possible, production location. Our analysis was not concerned with relating specific cultivars or production practices to the GBS concentrations, but rather, we aimed to capture diverse GBS concentrations so that we had a wide sample range from which to develop calibration models that were robust enough to work across many cultivars. To further increase the variability within each sample, cabbage heads were divided into wrapper, inner, and core tissue as we have observed variation among these tissues previously. Plants were used for analysis one to five days after purchase. From previous experiments, the authors have found that GBS concentration in cabbage stored at $98 \%$ relative humidity and $2^{\circ} \mathrm{C}$ was not significantly reduced over three months (Fritz, unpublished data). Each sample was split into two parts, one part to be used for wet chemistry analysis and the other for NIRS. The sample was chopped to approximately $2 \mathrm{~cm}$ square pieces and mixed to ensure homogeneity. Half of the sample was flash frozen for later lyophilization, and the remaining half was immediately placed in boiling water to begin sample preparation for HPLC analysis.

Chemical quantification of GBS. GBS was quantified as described by Hecht et al. [36] using modifications from Rosen et al. [37]. Samples of 100 to $150 \mathrm{~g}$ fresh weight were boiled in water in a volume of water threetimes their weight for five minutes to deactivate myrosinase. Samples were cooled at room temperature for ten 

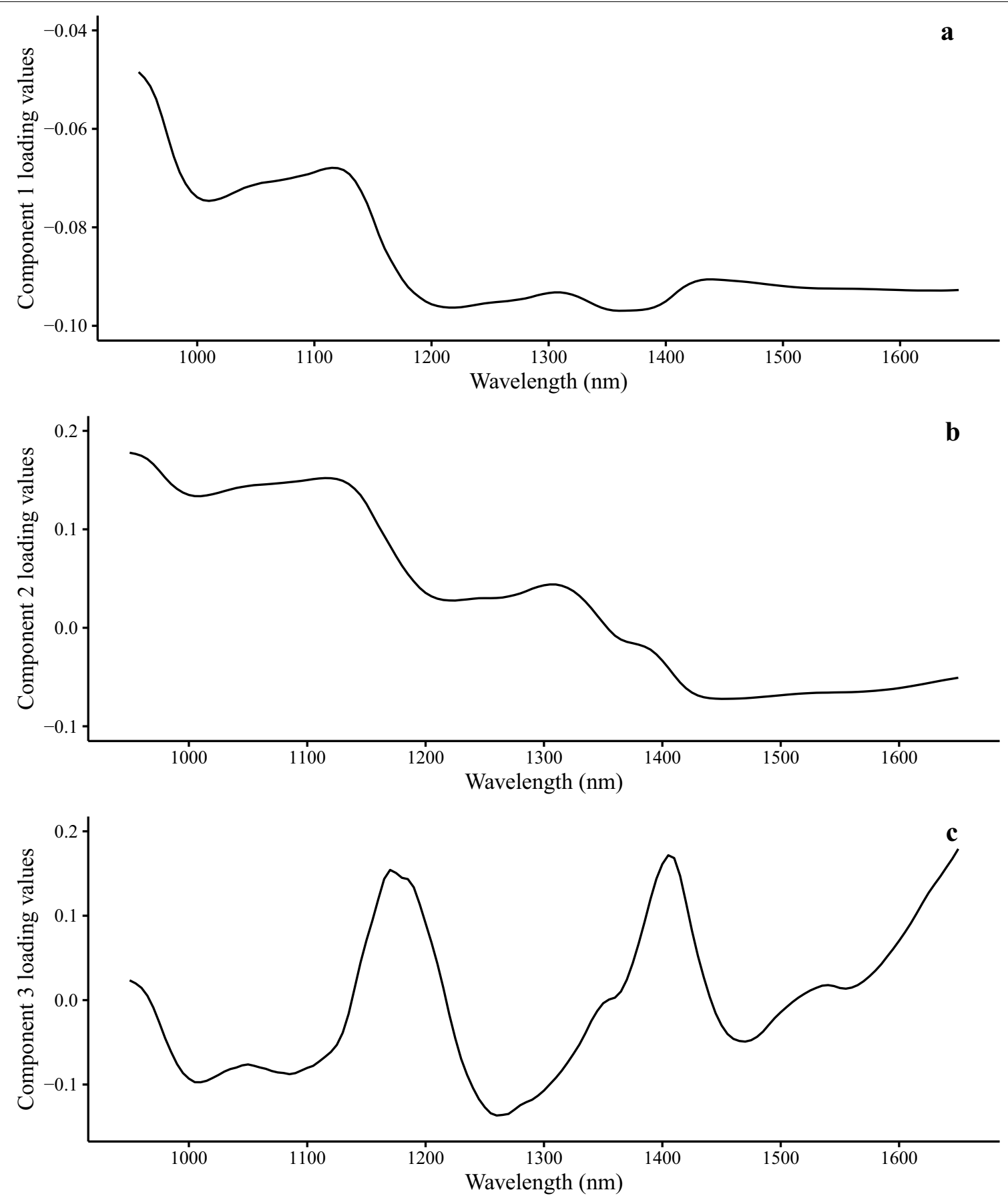

Fig. 5 First $\mathbf{a}$, second $\mathbf{b}$, and third $\mathbf{c}$ partial least squares (PLS) regression model factor loading values from the raw spectra model for predicting glucobrassicin (GBS) concentration from cabbage and Brussels sprouts. Vegetables were purchased from grocery stores and natural food cooperatives in Minneapolis and Saint Paul, MN between August and October, 2019. PLS regression models were developed to predict both fresh weight and dry weight GBS concentrations. Factor loading values from both models were the same so only one set is represented

minutes, then macerated in a blender for two minutes, then a $40-\mathrm{mL}$ aliquot of blended sample was stored at $-30^{\circ} \mathrm{C}$ until further analysis which occurred within 30 days. Later, samples were thawed and homogenized for two minutes at 12,000 rpm with a Polytron PT 1300 D homogenizer (Kinematica AG, Lucerne, Switzerland), and then 2-mL sample of the homogenate was centrifuged for $4 \mathrm{~min}$ at $8000 \mathrm{~g}$ at $4^{\circ} \mathrm{C}$. 
Desulfonated GSLs were extracted from the supernatant with solid phase strong anion exchange (SAX) columns (Sigma-Aldrich, St. Louis, MO). In a vacuum manifold, SAX columns were washed with $2 \mathrm{~mL}$ of $0.50 \mathrm{M}$ sodium acetate buffer ( $\mathrm{pH} 4.6$ ), followed by $2 \mathrm{~mL}$ of deionized water. $500 \mu \mathrm{L}$ of supernatant from centrifuged samples were filtered through columns followed by $1 \mathrm{~mL}$ of $0.02 \mathrm{M}$ sodium acetate ( $\mathrm{pH} 4.0)$ buffer. Finally, $1 \mathrm{~mL}$ of $0.2 \mathrm{mg} \cdot \mathrm{mL}^{-1}$ sulfatase solution (aryl-sulfate sulfohydrolase from Helix pomatia-Type H-1; SigmaAldrich, St. Louis, MO) was vacuum-infiltrated through the columns. Columns were incubated for $\sim 15 \mathrm{~h}$ at room temperature before elution with $3 \mathrm{~mL}$ of water (elution occurred in two steps, first with $2 \mathrm{~mL}$ and then with $1 \mathrm{~mL}$ ) and collected volumes were determined by weight. Eluents were stored at $-30^{\circ} \mathrm{C}$ until HPLC analysis which occurred within 14 days.

HPLC analysis was carried out using an Agilent 1200 Series Quaternary system (Agilent Technologies, Inc., Santa Clara, CA), with the diode array detector set at $\lambda=229 \mathrm{~nm}$, using a Luna C18, $5 \mu \mathrm{m}, 250 \times 4.6 \mathrm{~mm}$ guard column (Phenomenex, Torrence, CA) set at $30^{\circ} \mathrm{C} .50 \mu \mathrm{L}$ of eluent was injected and separated on the column with the following flow rates and gradients: $0-2 \mathrm{~min}$ gradient $5-15 \%$ acetonitrile, $1 \mathrm{~mL} / \mathrm{min} ; 2-20 \mathrm{~min}$ gradient $15-47 \%$ acetonitrile, $1 \mathrm{~mL} / \mathrm{min} ; 20-22 \mathrm{~min}$ gradient $47-100 \%$ acetonitrile, $1-1.15 \mathrm{~mL} / \mathrm{min} ; 22-26 \mathrm{~min}, 100 \%$ acetonitrile, gradient 1.15 to $1.3 \mathrm{~mL} / \mathrm{min} ; 26-28 \mathrm{~min}$, $100 \%$ acetonitrile, gradient $1.3-1.5 \mathrm{~mL} / \mathrm{min} ; 28-35 \mathrm{~min}$, $5 \%$ acetonitrile, $1 \mathrm{~mL} / \mathrm{min}$. GSL peaks were viewed in OpenLAB Chromatography Data System with rev. C.01.06 software and GBS was identified based on retention time. Concentration was determined using sinigrin as an external standard and previously published response factors [38].

Near-infrared reflectance spectroscopy (NIRS) analysis. Plant samples of 80 to $150 \mathrm{~g}$ were wrapped in aluminum foil, flash frozen in liquid nitrogen, placed on dry ice, and stored at $-80^{\circ} \mathrm{C}$ (S-7805, Uline, Pleasant Prairie, WI) until lyophilization. Frozen samples were placed inside a $35 \mathrm{~L}$ VirTis $24 \mathrm{Dx} 48$ general purpose freeze dryer (SP Scientific, Stone Ridge, NY, USA) which was kept at $-30^{\circ} \mathrm{C}$ for seven days, then after one week the temperature was raised to $-20^{\circ} \mathrm{C}, 24 \mathrm{~h}$ later it was raised again to $-10{ }^{\circ} \mathrm{C}$, and $24 \mathrm{~h}$ later the temperature was then allowed to slowly raise over 3 days until it achieved room temperature and samples were then removed. Freeze-dried samples of $\sim 10 \mathrm{~g}$ were preground in a 12-cup electric coffee grinder and further ground using a Retsch ZM200 (Retsch group, Haan, Germany) grinder with 35 mesh (0.5-mm particle size). Between grinding different samples, the mesh was removed and cleaned with a brush and pressurized air to avoid cross contamination. Samples were stored in small coin envelopes (S-14719, Uline, Pleasant Prairie, WI), packed with indicating silica gel desiccant packets (MiniPax absorbent packets, Sigma-Aldrich, Saint Louis, MO), and stored inside an airtight container with for up to two weeks prior to NIRS analysis.

Diffuse reflectance NIRS was applied using a diode array NIRS instrument (DA 7250 NIR Analyzer; Perten Instruments, Hägersten, Sweden). For each NIRS scan, a 10-g sample of freeze-dried cabbage or Brussels sprout leaf tissue was placed in a $22-\mathrm{ml}$ volume NIRS sample dish by pouring the powdered sample into the dish and using a straight edge to scrap off any extra sample so that the surface was consistent across all scans. The minimum quantity of freeze-dried sample needed for each NIR scan was related to the size of the sample dish. For our samples, approximately $10-\mathrm{g}$ of leaf tissue was sufficient to slightly overfill the sample dish so excess could be scraped off. Each of the 92 samples were scanned twice for a total of 184 scans. The average spectrum of each induvial sample was calculated. The calibration models were developed using the average spectrum of each of the 92 individual samples. NIRS scans were taken in the wavelength range of 950 to $1650 \mathrm{~nm}$ at an interval of $5 \mathrm{~nm}$. Testing and training data sets were split using a stratified random sampling procedure to split the data into calibration $(n=68)$ and validation $(\mathrm{n}=24)$ data sets. Calibration and validation were performed with $\mathrm{R}$ Statistical software version 3.2.4 [39] using the pls package [40]. An additional data file generated for chemometrics are included [Additional file 1].

\section{Supplementary information}

Supplementary information accompanies this paper at https://doi. org/10.1186/s13007-020-00681-7.

Additional file 1. Description of data: NIRS spectra between 950 and $1650 \mathrm{~nm}$ recorded as the log of $1 /$ reflectance.

\section{Abbreviations}

GBS: Glucobrassicin; GSL: Glucosinolate; HPLC: High-performance liquid chromatography; NIRS: Near infrared spectroscopy; PLSR: Partial least squares regression; $R_{\text {cal }}^{2}$ : Coefficient of determination of calibration; $R_{c v}^{2}$ : Coefficient of determination of cross-validation; RMSEP: Root mean squared error of prediction; RMSEC: Room mean squared error of calibration; RPD: Ratio of prediction to deviation; SECV: Standard error of cross-validation; SNV: Standard normal variate.

\section{Acknowledgements}

We would like to thank Gary Gardner, Jerry Cohen, Roger Becker, and Julie Grossman, all of whom edited this manuscript. We would also like to thank Joshua Anderson for the assistance in R script development for PLSR modeling.

This paper is a part of a dissertation submitted by the first author in fulfilling a degree requirement. 


\section{Authors' contributions}

IR designed this experiment, collected data, conducted statistical analyses, interpreted results, and wrote the manuscript. VF prompted the experimental concept and edited the manuscript. Both authors read and approved the final manuscript.

\section{Funding}

This research was funded by the Minnesota Agricultural Experiment Station.

\section{Availability of data and materials}

All data generated or analyzed during this study are included in this published article [and its supplementary information files [see additional file: NIR_GBS_ Chemometrics.xls]

\section{Ethics approval and consent to participate}

Not applicable.

\section{Consent for publication}

Not applicable.

\section{Competing interests}

The authors declare that they have no competing interests.

\section{Author details}

${ }^{1}$ Department of Horticultural Science, University of Minnesota, Saint Paul, MN 55108, USA. ${ }^{2}$ Southern Research and Outreach Center, University of Minnesota, Waseca, MN 56093, USA.

Received: 17 July 2020 Accepted: 6 October 2020 Published online: 12 October 2020

\section{References}

1. Halkier BA, Gershenzon J. Biology and biochemistry of glucosinolates. Ann Rev Plant Biol. 2006;57:303-33.

2. Hopkins RJ, van Dam NM, van Loon JJ. Role of glucosinolates in insectplant relationships and multitrophic interactions. Annu Rev Entomol. 2009;54:57-83.

3. Tierens KFJ, Thomma BP, Brouwer M, Schmidt J, Kistner K, Porzel A, Mauch-Mani B, Cammue BPA, Broekaert WF. Study of the role of antimicrobial glucosinolate-derived isothiocyanates in resistance of Arabidopsis to microbial pathogens. Plant Physiol. 2001;125(4):1688-99.

4. Blažević I, Montaut S, Burčul F, Olsen CE, Burow M, Rollin P, Agerbirk N. Glucosinolate structural diversity, identification, chemical synthesis and metabolism in plants. Phytochemistry. 2019;168:112100.

5. Higdon JV, Delage B, Williams DE, Dashwood RH. Cruciferous vegetables and human cancer risk: epidemiologic evidence and mechanistic basis. Pharmacol Res. 2007;55(3):224-36.

6. Wittstock U, Halkier BA. Glucosinolate research in the Arabidopsis era. Trends Plant Sci. 2002;7(6):263-70.

7. Fujioka N, Fritz V, Upadhyaya P, Kassie F, Hecht SS. Research on cruciferous vegetables, indole-3-carbinol, and cancer prevention: a tribute to Lee W Wattenberg. Mol Nutr Food Res. 2016;60(6):1228-38.

8. Wattenberg LW. Studies of polycyclic hydrocarbon hydroxylases of the intestine possibly related to cancer: effect of diet on benzpyrene hydroxylase activity. Cancer. 1971;28(1):99-102

9. Loub WD, Wattenberg LW, Davis DW. Aryl hydrocarbon hydroxylase induction in rat tissues by naturally occurring indoles of cruciferous plants. J Natl Cancer Inst. 1975;54(4):985-8.

10. Kassie F, Anderson LB, Scherber R, Yu N, Lahti D, Upadhyaya P, Hecht SS. Indole-3-carbinol inhibits 4-(methylnitrosamino)-1-(3-pyridyl)-1butanone plus benzo (a) pyrene-induced lung tumorigenesis in A/J mice and modulates carcinogen-induced alterations in protein levels. Cancer Res. 2007;67(13):6502-11.

11. Morse MA, LaGreca SD, Amin SG, Chung FL. Effects of indole3-carbinol on lung tumorigenesis and DNA methylation induced by 4-(methylnitrosamino)-1-(3-pyridyl)-1-butanone (NNK) and on the metabolism and disposition of NNK in A/J mice. Cancer Res. 1990:50(9):2613-7.
12. Taioli E, Garbers S, Bradlow HL, Carmella SG, Akerkar S, Hecht SS. Effects of indole-3-carbinol on the metabolism of 4-(methylnitrosamino)-1(3-pyridyl)-1-butanone in smokers. Cancer Epidemiol Biomarkers Prev. 1997;6(7):517-22.

13. Vanamala J. Food systems approach to cancer prevention. Crit Rev Food Sci Nutr. 2007;57(12):2573-88.

14. Charron CS, Saxton AM, Sams CE. Relationship of climate and genotype to seasonal variation in the glucosinolate-myrosinase system. I. Glucosinolate content in ten cultivars of Brassica oleracea grown in fall and spring seasons. J Sci Food Agric. 2005;85(4):671-81.

15. Real V, Heaney PR, Fenwick GR, Portas CAM. Glucosinolates in crop plants. Hortic Rev. 2010;55:99.

16. Horbowicz M. The occurrence, role and contents of glucosinolates in Brassica vegetables. Veg Crops Res Bull. 2003;58:23-40.

17. ISO 9167-1, 1992 NA 057-05-05 AA-Joint committee of DIN and DGF for the analysis of fats, oils and products thereof, related and primary products. (2012): rapeseed-determination of glucosinolate contentpart 1: method using high-performance liquid chromatography (ISO 9167-1:1992/DAM 1:2012), German version EN ISO 9167-1:1995/prA1: 2012.).

18. Workman J. Interpretive spectroscopy for near infrared. Appl Spectrosc Rev. 1996;31(3):251-32020.

19. Raghavachari R. Near-infrared applications in biotechnology. Boca Raton: CRC Press; 2000

20. Wold S, Sjöström M, Eriksson L. PLS-regression: a basic tool of chemometrics. Chemom Intell Lab Syst. 2001;58(2):109-30.

21. Kumar S, Chauhan JS, Kumar A. Screening for erucic acid and glucosinolate content in rapeseed-mustard seeds using near infrared reflectance spectroscopy. J Food Sci Technol. 2010;47(60):690-2.

22. Geladi P, Kowalski BR. Partial least-squares regression: a tutorial. Anal Chim Acta. 1986:185:1-7.

23. Cheng B, Wu X. A modified PLSR method in prediction. J Data Sci. 2006:4:257-74

24. Li X, Wu L, Qiu G, Wang T, Liu C, Yang Y, Feng B, Chen C, Zhang W, Liu Z. Effects of sowing season on agronomic traits and fatty acid metabolic profiling in three Brassica napus L. cultivars. Metabolites. 2019;9(2):37.

25. Font R, Del Río-Celestino M, Rosa E, Aires A, De Haro-Bailón A Glucosinolate assessment in Brassica oleracea leaves by near-infrared spectroscopy. J Agric Sci. 2005;143(1):65-73.

26. Toledo-Martín EM, Font R, Obregón-Cano S, De Haro-Bailón A, VillatoroPulido M, Del Río-Celestino M. Rapid and cost-effective quantification of glucosinolates and total phenolic content in rocket leaves by visible/near-infrared spectroscopy. Molecules. 2017;22(5):851.

27. Sahamishirazi S, Zikeli S, Fleck M, Claupein W, Graeff-Hoenninger S. Development of a near-infrared spectroscopy method (NIRS) for fast analysis of total, indolic, aliphatic and individual glucosinolates in new bred open pollinating genotypes of broccoli (Brassica oleracea convar. botrytis var. italica). Food Chem. 2017;232:272-7.

28. Font R, Del Rìo-Celestino M, Cartea E, De Haro-Bailón A. Quantification of glucosinolates in leaves of leaf rape (Brassica napus ssp pabularia) by near-infrared spectroscopy. Phytochemistry. 2005:66:175-85.

29. Hernández-Hierro JM, Valverde J, Villacreces S, Reilly K, Gaffney M, González-Miret ML, Heredia FJ, Downey G. Feasibility study on the use of visible-near-infrared spectroscopy for the screening of individual and total glucosinolate contents in broccoli. J Agric Food Chem. 2012;60(30):735288.

30. Chen J, Li L, Wang S, Tao X, Wang Y, Sun A, He H. Assessment of glucosinolates in Chinese kale by near-infrared spectroscopy. Int J Food Prop. 2014;17(8):1668-799.

31. Workman J. Concise handbook of analytical spectroscopy, the: theory, applications, and reference materials. Singapore: World Scientific; 2016.

32. Barnes RJ, Dhanoa MS, Lister SJ. Standard normal variate transformation and de-trending of near-infrared diffuse reflectance spectra. Appl Spectrosc. 1989;43(5):772-7.

33. Hastie T, Tibshirani R, Friedman J. The elements of statistical learning: data mining, inference, and prediction. 2nd ed. New York: SpringerVerlag; 2009.

34. Wiklund S, Nilsson D, Eriksson L, Sjöström M, Wold S, Faber K. A randomization test for PLS component selection. J Chemom. 2007;21(10-11):427-39. 
35. Saeys W, Mouazen AM, Ramon H. Potential for onsite and online analysis of pig manure using visible and near infrared reflectance spectroscopy. Biosyst Eng. 2005;91(4):393-402.

36. Hecht SS, Carmella SG, Kenney PMJ, Low SH, Arakawa K, Yu MC. Effects of cruciferous vegetable consumption on urinary metabolites of the tobacco-specific lung carcinogen 4-(methylnitrosamino)-1-(3-pyridyl)1-butanone in Singapore Chinese. Cancer Epidemiol Biomarkers Prev. 2004;13(6):997-1004.

37. Rosen CJ, Fritz VA, Gardner GM, Hecht SS, Carmella SG, Kenney PM. Cabbage yield and glucosinolate concentrations as affected by nitrogen and sulfur fertility. HortSci. 2005;40(5):1493-8.
38. EU. Determination of glucosinolates in oilseeds by liquid chromatography (HPLC). Off J Eur Commun Legis. 1990;170(0307):27-34.

39. R Core Team. R. A Language and environment for statistical computing. Vienna: R Foundation for Statistical Computing; 2016.

40. Wehrens R, Mevik BH. The pls package: principal component and partial least squares regression in R. J Stat Softw. 2007;18(2):1-23.

\section{Publisher's Note}

Springer Nature remains neutral with regard to jurisdictional claims in published maps and institutional affiliations.
Ready to submit your research? Choose BMC and benefit from:

- fast, convenient online submission

- thorough peer review by experienced researchers in your field

- rapid publication on acceptance

- support for research data, including large and complex data types

- gold Open Access which fosters wider collaboration and increased citations

- maximum visibility for your research: over 100M website views per year

At BMC, research is always in progress.

Learn more biomedcentral.com/submissions 